\title{
DG integration to distribution system with active power injection control
}

\author{
P. V. V Satyanarayana, P. V. Ramana Rao
}

Departement of Electrical and Electronics Engineering, Acharya Nagarjuna University, India

\begin{tabular}{|c|c|}
\hline Article Info & ABSTRACT \\
\hline Article history: & Conventional methodology for electrical power generation is vulnerable due \\
\hline Received Jul 31, 2019 & $\begin{array}{l}\text { to environmental limitations and the availability of fuel. Distributed } \\
\text { generation, offering virtuous benefits to the market partakers, is trending in }\end{array}$ \\
\hline Revised Nov 9, 2019 & electrical power system in modern era. This paper presents the distributed \\
\hline Accepted Dec 3, 2019 & $\begin{array}{l}\text { generation integration to grid with active power injection control. Distributed } \\
\text { generation source delivers DC power which is processed through square }\end{array}$ \\
\hline Keywords: & $\begin{array}{l}\text { wave inverter. Inverter circuit is controlled using a simple control technique } \\
\text { to match grid code. Fixing the current reference and varying the same, }\end{array}$ \\
\hline Active Power & analysis is carried out for grid integration scheme of distributed generation \\
\hline Current Reference & injecting active power to grid. Simulation work is carried out and results are \\
\hline Distributed Generation & \\
\hline
\end{tabular}

Grid

Integration

This is an open access article under the CC BY-SA license.

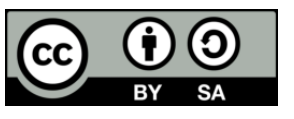

\section{Corresponding Author:}

P. V. V. Satyanarayana,

Research Scholar, Departement of Electrical and Electronics Engineering,

Acharya Nagarjuna University, Guntur, AP, India.

Email: pvvsatyanarayana.eee@gmail.com

\section{INTRODUCTION}

Majority of the electrical energy worldwide is generated bulk (about $1 \mathrm{MW}$ to $1000 \mathrm{MW}$ ) power plants and is delivered to consumers through electrical transmission and distribution systems. This type of power system is generally termed 'centralized power system'. This electrical energy is generated from combustion fuels (like coal, natural gas or oil) or nuclear fuels [1]. The main constraints with the usage of conventional fuels are pollution and availability [2-3]. Conventional fuels are at extinct point now-a-days and cost more. Conventional power plants are a constraint these days as the world countries are focusing on issues regarding global warming. Distributed generation is a viable option to reduce pollution and also to address many technical issues regarding conventional power generation. Distributed generation is the generation at load side reducing the transmission losses considerably [4-8]. Generation of electrical energy from the source which are renewable in nature are called renewable energy sources like solar, wind etc. Distributed generation has penetrated in many of the European countries in the last few years. Power generation near or at the load points or at the point of use is termed as "Distributed generation" [9-16]. Many renewable sources like photo-voltaic system, small wind turbines are capable of generating electrical energy at distribution point [17-20]. Climatic change guidelines, advancements in technology and increase in prospects of customers led to increased usage of DGs. Figure 1 shows the scope of renewable sources. This paper presents the distributed generation integration to grid [21-26] with active power injection control. Distributed generation source delivers DC power which is processed through square wave inverter [27]. Inverter circuit is controlled using a simple control technique to match grid code. Fixing the current reference and varying the same, analysis is carried out for grid integration scheme of distributed generation injecting 
active power to grid. Simulation work is carried out and results are shown using MATLAB/SIMULINK software.

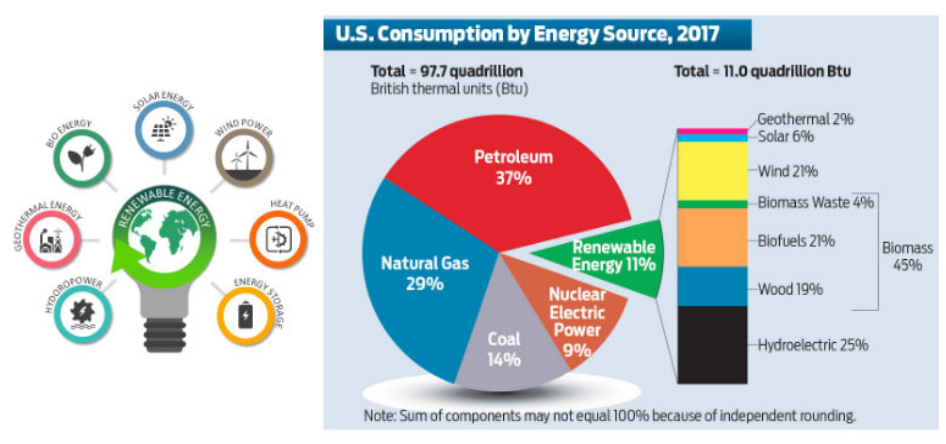

Figure 1. Scope of renewable sources

\section{DISTRIBUTED GENERATION INTEGRATION TO GRID}

Distributed generation (DG) or distributed energy resources (DER) are the supplying reserves of electrical energy which are directly connected to the local distribution system. Many renewable sources like photo-voltaic system, small wind turbines are capable of generating electrical energy at distribution point. Distributed generation more often involve off-grid (also called as isolated) type or grid connected (nonisolated) mode operations. Off-grid distributed generation generally provides its (DG's) self generated electricity to the end users and is isolated from the main electrical grid. On the other hand, grid connected distributed system is the local generating system connected to main grid. Distributed generation units can be combined to make a small grid and these small grids can be connected to large/centralized grid to stabilize the main grid. Figure 2 illustrates the Distributed Generation integration scheme to Grid. The output of Distributed energy resource (DER) is fed to DG inverter. DC power output from the DER is inverted to AC type using DG inverter. The quasi-square output from the DG inverter is further smoothened using interfacing inductors and supplies active power to grid.

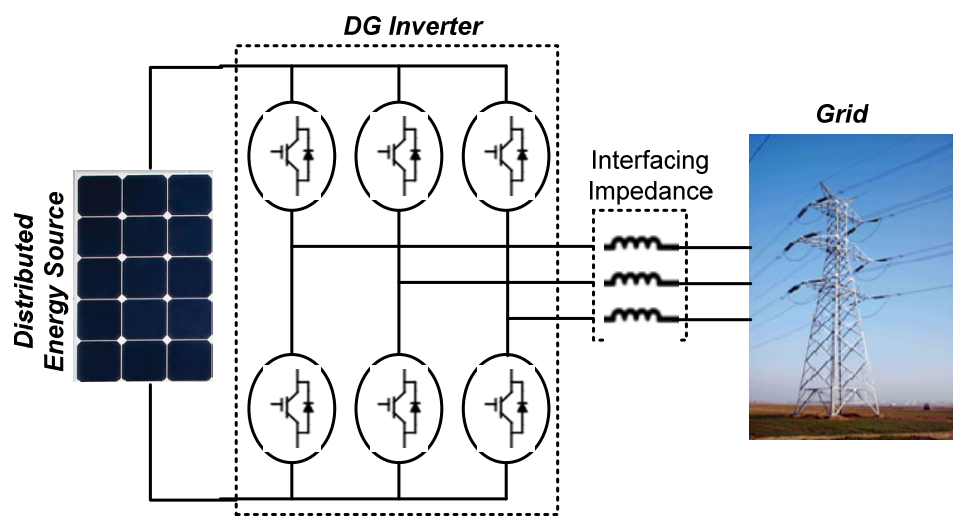

Figure 2. Distributed Generation integration scheme to grid

\section{CONTROL STRATEGY FOR ACTIVE POWER INJECTION FROM DG TO GRID}

Control methodology for active power injection from DG to grid is shown in Figure 3. The control strategy to control the DG (square wave) inverter to inject active power to grid is a simple d-q theory. Initially, a phase sequence signal is extracted which is synchronized on zero crossings of fundamental phase from the three-phase source voltage (using a PLL block). Using inverse Parks transformation as in equation (1), the rotating frame time domain ' $\mathrm{d}-\mathrm{q}$ ' components are transformed to three-phase 'abc' reference frame. 


$$
\left[\begin{array}{l}
I_{a} \\
I_{b} \\
I_{c}
\end{array}\right]=\sqrt{2 / 3}\left[\begin{array}{ccc}
\cos (\theta) & -\sin (\theta) & \sqrt{\frac{1}{2}} \\
\cos (\theta-2 \pi / 3) & -\sin (\theta-2 \pi / 3) & \sqrt{\frac{1}{2}} \\
\cos (\theta+2 \pi / 3) & -\sin (\theta+2 \pi / 3) & \sqrt{\frac{1}{2}}
\end{array}\right]\left[\begin{array}{c}
I_{d} \\
I_{q} \\
I_{0}
\end{array}\right]
$$

Balanced system makes zero-component zero. The three-phase reference currents are compared with actual three-phase currents to generate pulses to square wave (DG) inverter switches. Complete schematic arrangement of DG integrated to grid with corresponding control circuit is represented diagrammatically in Figure 4. While integrating the system, the control unit generates the signals such that the DG inverter output parameters match the grid code. Table 1 illustrates the system parameters used for the simulation analysis.

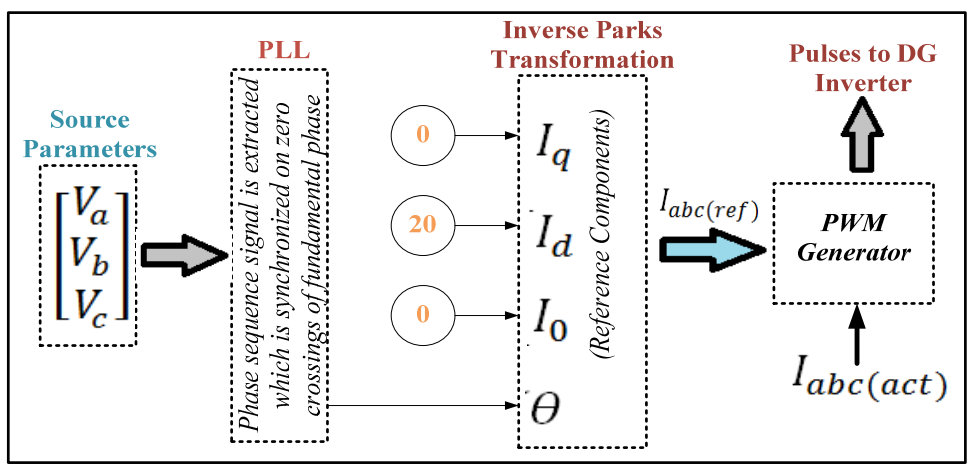

Figure 3. Control methodology for active power injection from DG to grid

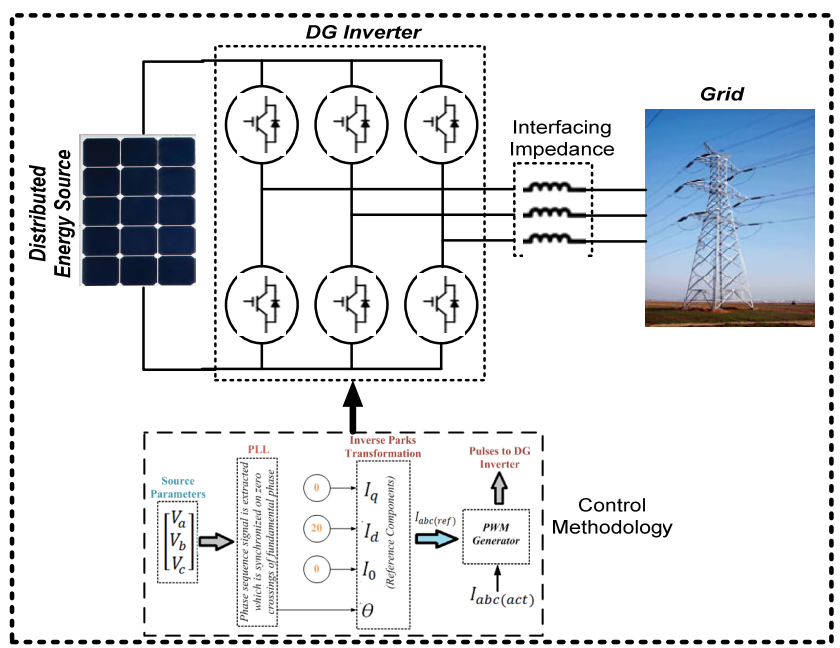

Figure 4. Schematic arrangement of grid interfacing scheme of DG with control methodology

Table 1. System Parameters

\begin{tabular}{cc}
\hline Paramete & Value \\
\hline DC Input Source & $800 \mathrm{~V}$ \\
Interfacing Inductor & $7.5 \mathrm{mH}$ \\
Grid Parameters & $440 \mathrm{~V}, 50 \mathrm{~Hz}$ \\
\hline
\end{tabular}

Int J Pow Elec \& Dri Syst, Vol. 11, No. 2, June 2020 : $692-701$ 


\section{SIMULATION RESULTS AND ANALYSIS}

\subsection{Active power injection from DG to grid with fixed current refrence}

Figure 5 shows the voltage induced to grid from DG. Three-phase voltages with magnitude 360V are induced to grid along with three-phase currents of magnitude 20A. The illustration of Three-phase currents is made in Figure 6.

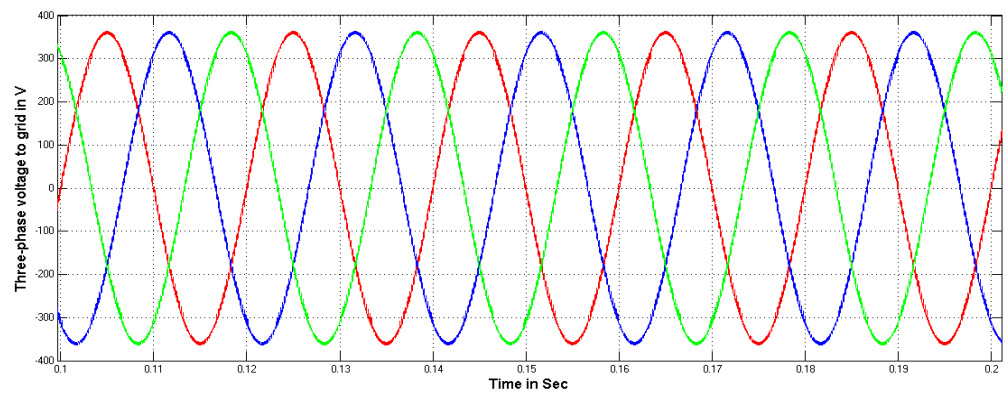

Figure 5. Three-phase Voltages induced to grid

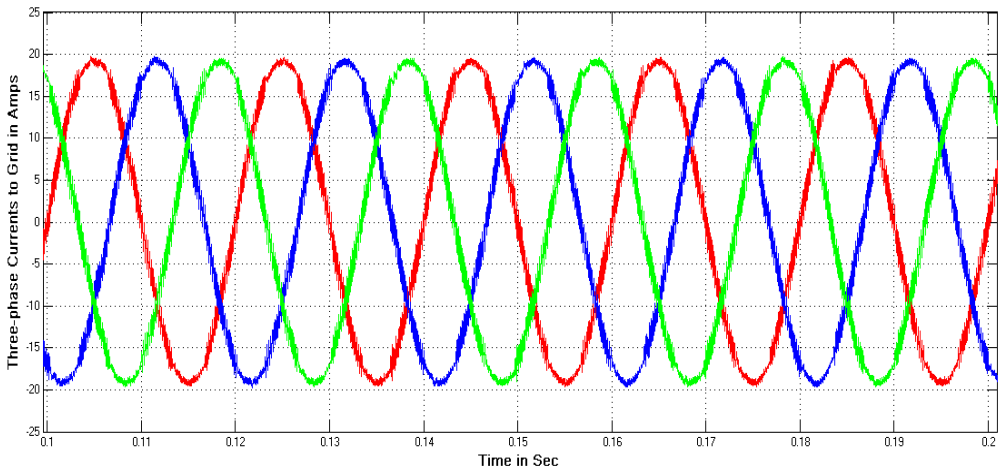

Figure 6. Three-phase currents induced to grid

The phase angle difference between induced voltage and induced current is shown in Figure 7 . The phase angle is observed almost zero making the power factor near to unity as demanded. Gain of current signal is increased for clear visualization.

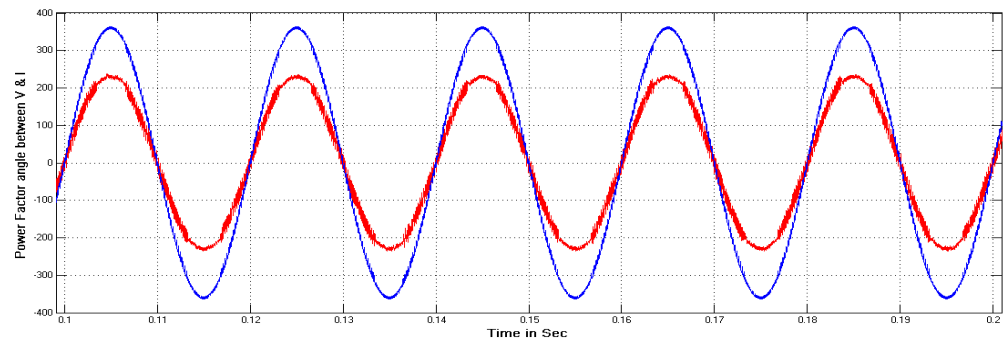

Figure 7. Power factor angle between induced voltage and current

Figure 8 indicates the active power fed to grid from DG and Figure 9 illustrates the reactive power exchange between grid and DG system. Active power of $10.4 \mathrm{KW}$ is induced to grid from DG system and reactive power exchange is zero.

DG Integration to Distribution System with Active Power Injection Control ... (P. V. V Satyanarayana) 


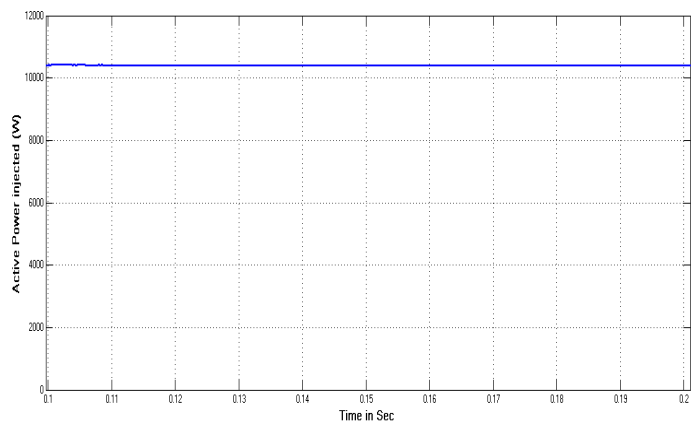

Figure 8. Active power fed to grid from DG

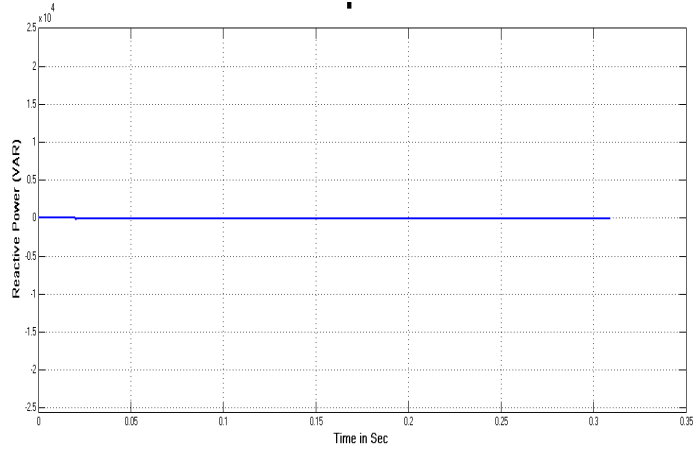

Figure 9. Reactive power fed to grid from DG

In Figure 10 is shown the line voltage of $800 \mathrm{~V}$ peak in each line of DG inverter. Whereas Figure 11 shows phase voltages with peak $535 \mathrm{~V}$.

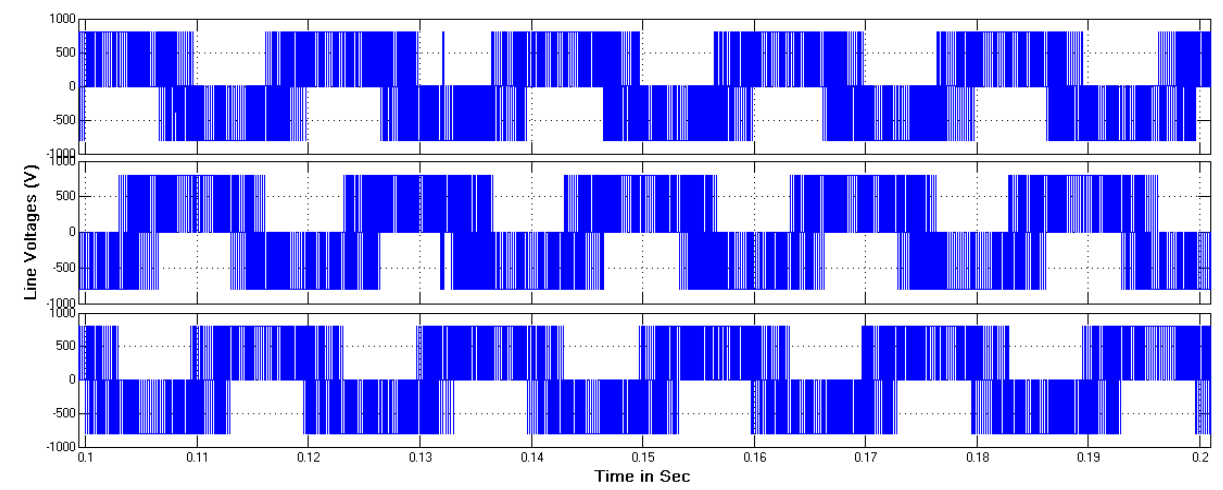

Figure 10. Line voltages of DG inverter

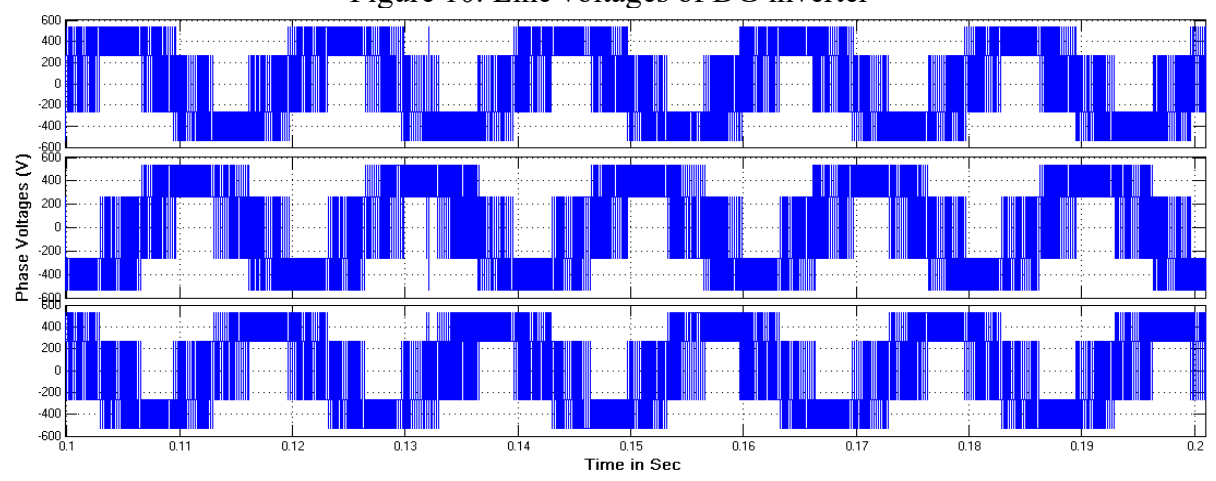

Figure 11. Phase voltages of DG inverter

Figure 12 shows the harmonic analysis of induced current from DG to grid. Induced current consists of harmonic content with magnitude $4.68 \%$ (of fundamental) which is within the prescribed limit. 


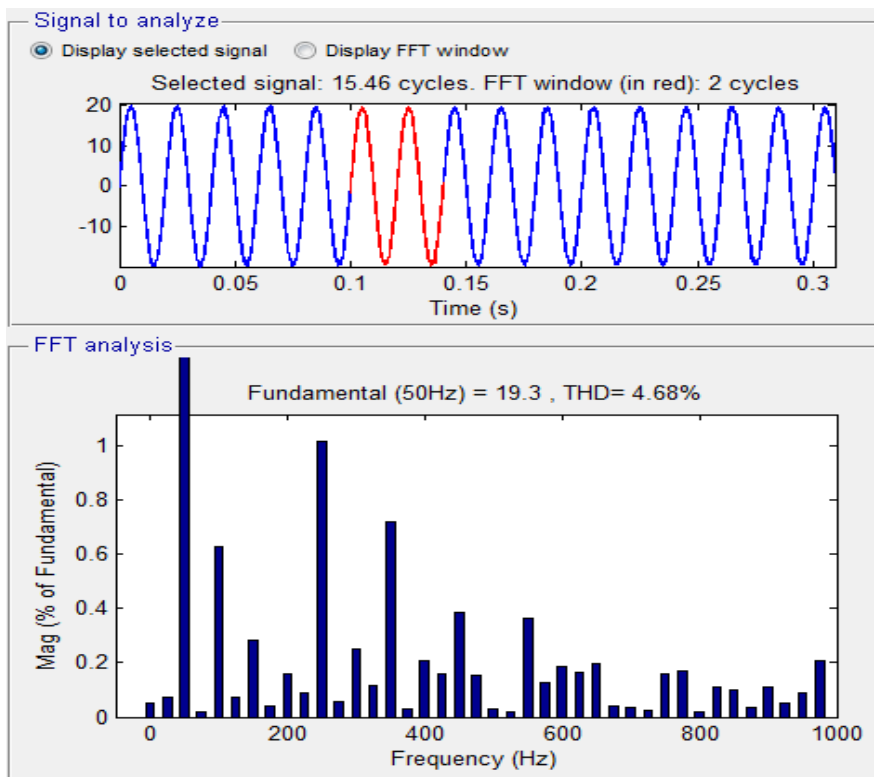

Figure 12. Harmonic analysis of induced current to grid

\subsection{Active power injection from DG to grid with variable current reference}

Figure 13 shows the voltage induced to grid from DG. Three-phase voltages with magnitude $360 \mathrm{~V}$ are induced to grid along with three-phase currents. The variable current reference command is given at $0.3 \mathrm{sec}$. Current is fed to grid with magnitude $20 \mathrm{~A}$ before change command, when the current reference signal is varied current peaks to 60A. The illustration of Three-phase currents is made in Figure 14.

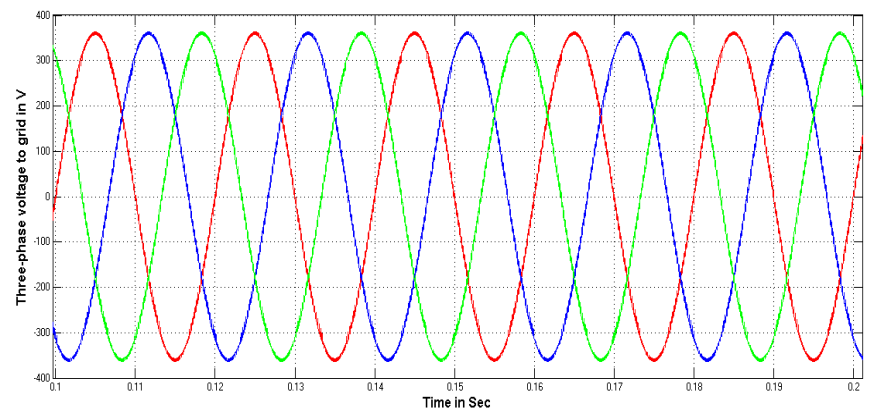

Figure 13. Three-phase Voltages induced to grid

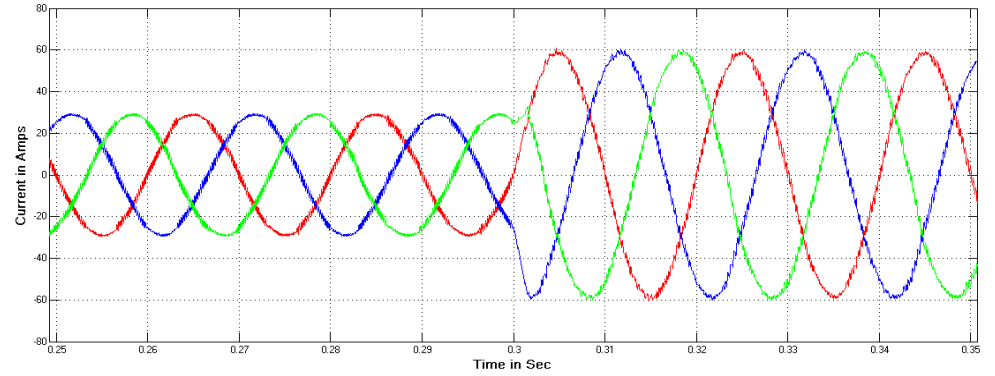

Figure 14. Three-phase currents induced to grid 
The phase angle difference between induced voltage and induced current with variable current reference is shown in Figure 15. The phase angle is observed almost zero making power factor near to unity as demanded. Gain of current signal is increased for clear visualization.

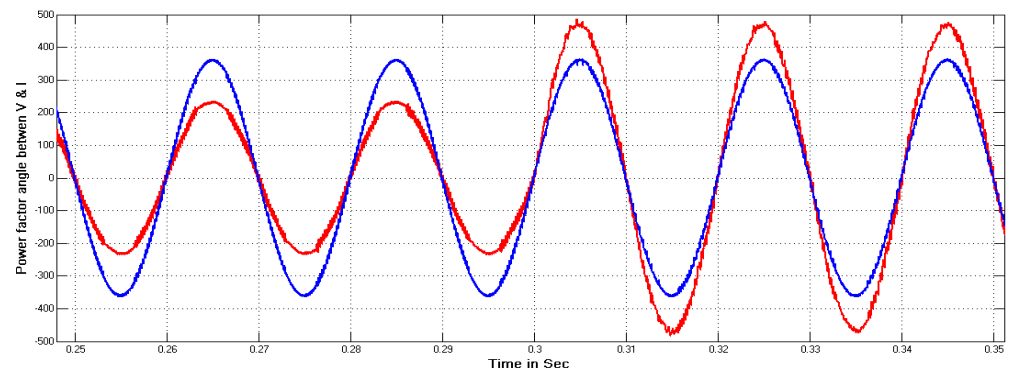

Figure 15. Power factor angle between induced voltage and current

Figure 16 indicates the active power fed to grid from DG and Figure 17 illustrates the reactive power exchange between grid and DG system with variable current reference. Active power of $15.65 \mathrm{KW}$ is induced to grid from DG system before current reference is varied and after varying, $31.6 \mathrm{KW}$ active power is fed to grid. Reactive power exchange is zero before and after variable current reference command.

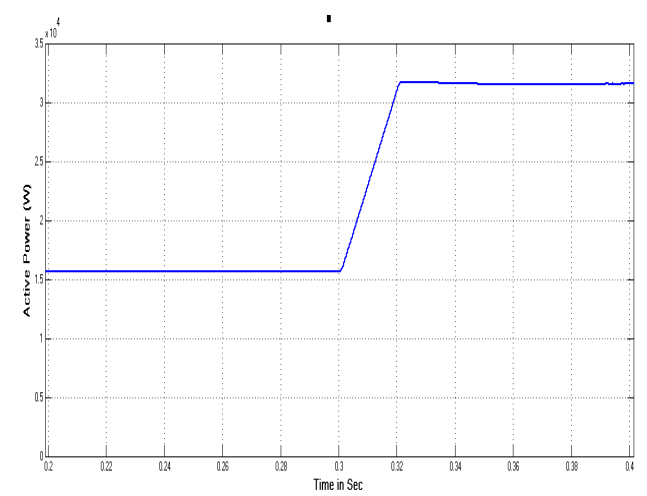

Figure 16. Active power fed to grid from DG

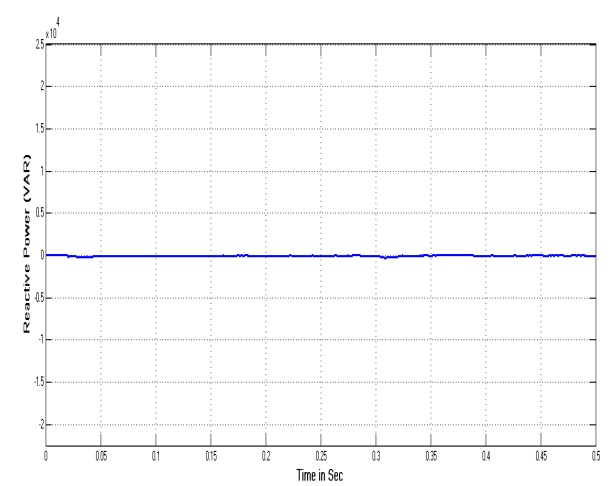

Figure 17. Reactive power fed to grid from DG

Figure 18 shows the line voltage of $800 \mathrm{~V}$ peak in each line of DG inverter. Figure 19 shows the phase voltages with peak $535 \mathrm{~V}$.

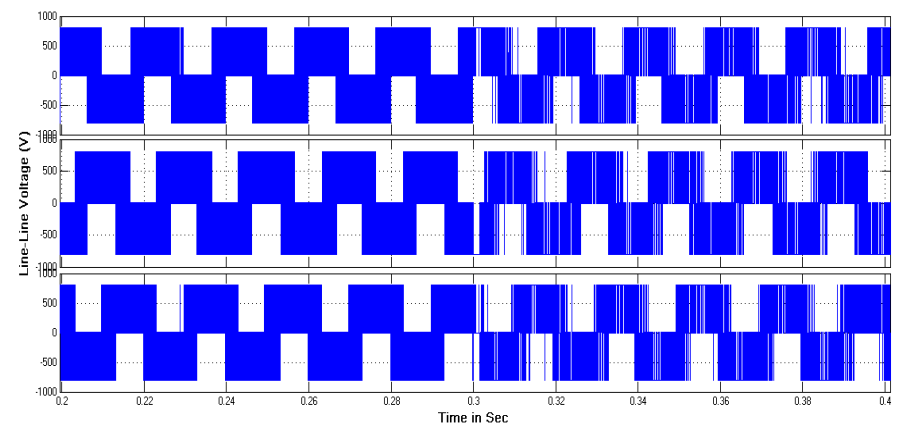

Figure 18. Line voltages of DG inverter 


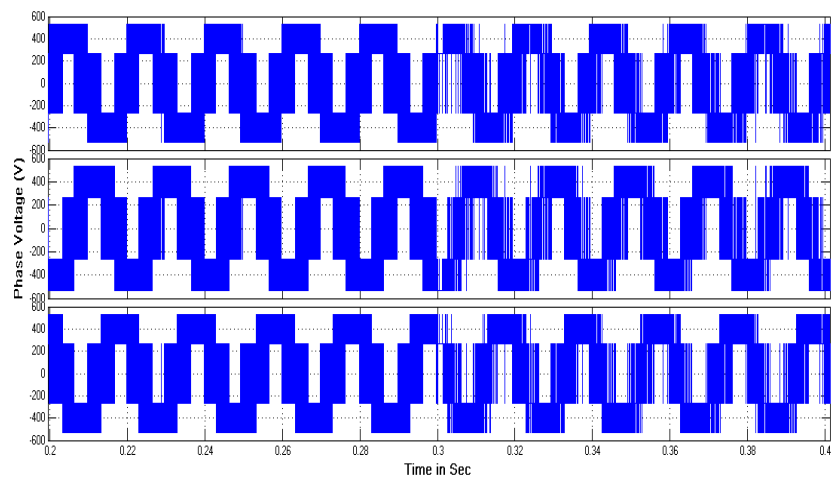

Figure 19. Phase voltages of DG inverter

Figure 20 shows the harmonic analysis of $4.80 \%$ in induced current from DG to grid before variable command. Figure 21 shows the harmonic analysis of $4.16 \%$ in induced current from DG to grid after variable command. In both the cases, before and after variable command, harmonic content is within the prescribed limits.

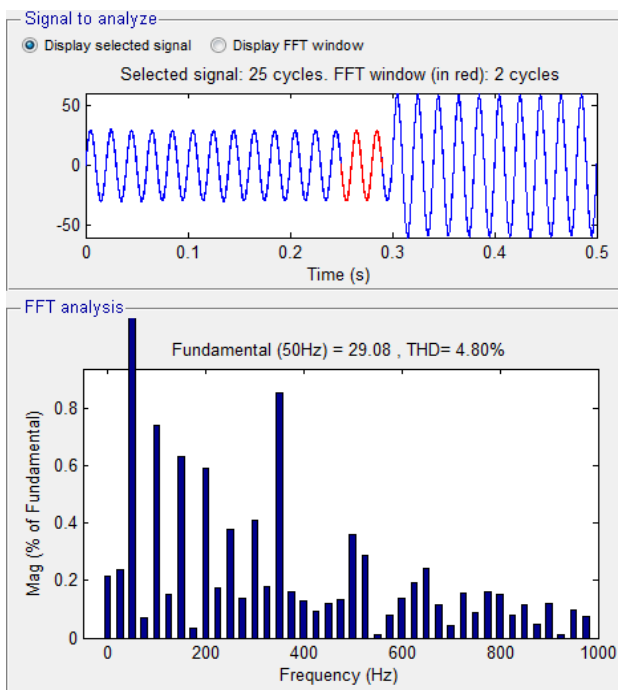

Figure 20. THD in source current before variable command
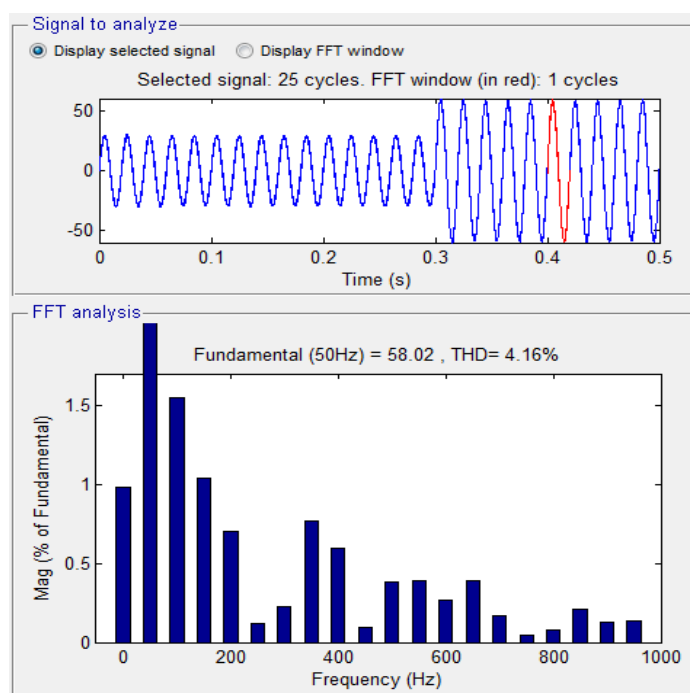

Figure 21. THD in source current after variable command

\section{CONCLUSION}

Sufficient reserve power from the DGs is very essential to provide a secure system and to maintain the power balance between the source and demand. The power generated from the distributed generation using a distributed energy resource fed to grid is discussed in this paper. The system configuration of DG integration to grid and the respective control algorithm for DG inverter for active power control is illustrated in this paper. Simulation analysis is done with fixed and variable current reference and results prove that the system injects active power to grid in both the conditions. Reactive power exchange between the grid and the integration system is zero and thus power factor is maintained nearer to unity. Harmonics in injected current are also within the prescribed limit. The active power injection control methodology for DG inverter is simple and not complex. 


\section{REFERENCES}

[1] R. N. Anthony and S. P. Navghare, "An insight to distributed generation of electrical energy from various renewable sources," 2016 International Conference on Energy Efficient Technologies for Sustainability (ICEETS), Nagercoil, 2016, pp. 341-344.

[2] R. Hledik J. Lazar L. Schwartz "Distribution System Pricing with Distributed Energy Resources” May 2016.

[3] Renewable Energy Capacity Statistics Mar. 2016

[4] DK2050: Green Growth in Denmark Towards 2050 - Four Future Scenarios Mar. 2017.

[5] Transforming the European Energy System Through Innovation-Integrated Strategic Energy Technology (SET) Plan Progress in 2016

[6] Renewables 2016: Global Status Report Mar. 2017

[7] F. Blaabjerg D. M. Ionel Y. Yang H. Wang "Renewable energy systems-Technology overview and perspectives" in Chapter 1 in Renewable Energy Devices and Systems with Simulations in MATLAB and ANSYS Boca Raton FL USA:CRC Press pp. 1-16 2017

[8] M. A. Zehir et al., "Identification and comparison of power and energy management capabilities of distributed energy resources," 2018 6th International Istanbul Smart Grids and Cities Congress and Fair (ICSG), Istanbul, 2018, pp. 119-123

[9] V. S. Pappala I. Erlich K. Rohrig J. Dobschinski "A stochastic model for the optimal operation of a wind-thermal power system" IEEE Trans. Power Syst. vol. 24 no. 2 pp. 940-950 May 2009.

[10] P. Ruiz P. C. Philbrick E. Zak K. W. Cheung P. Sauer "Uncertainty management in the unit commitment problem" IEEE Trans. Power Syst. vol. 24 no. 2 pp. 642-651 May 2009.

[11] C. Weber P. Meibom R. Barth H. Brand "WILMAR: A stochastic programming tool to analyze the large-scale integration of wind energy" in Optimization in the Energy Industry Berlin Germany: Springer-Verlag pp. 437-458 2009.

[12] A. Papavasiliou S. Oren R. P. O’Neill "Reserve requirements for wind power integration: A scenario-based stochastic programming framework" IEEE Trans. Power Syst. vol. 26 no. 4 pp. 2197-2206 Nov. 2011.

[13] D. Stimoniaris D. Tsiamitros E. Dialynas "Improved energy storage management and PV-active control infrastructure and strategies for microgrids" IEEE Transactions on Power System vol. 31 no. 1 pp. 813-820 January 2015

[14] D Sattianadan, K Saravanan, S. Murugan, N. Hari, P. Venkadesh, "Implementation of quasi-z source inverter for grid connected PV based charging station of electric vehicle", International Journal of Power Electronics and Drive System (IJPEDS), Vol. 10, No. 1, pp. 366 373, March 2019.

[15] Mohamed Ibrahim A. Arafa, El-Sayed Soliman A. Said, "A different vision for uninterruptible load using hybrid solar-grid energy", International Journal of Power Electronics and Drive System (IJPEDS), Vol. 10, No. 1, pp. 381 387, March 2019.

[16] B. Kroposki et al. "Achieving a 100\% renewable grid: Operating electric power systems with extremely high levels of variable renewable energy" IEEE Power Energy Mag. vol. 15 no. 2 pp. 61-73 Mar. 2017.

[17] V. Knazkins "Stability of power systems with large amounts of distributed generation" 2004.

[18] Mahrous Ahmed, Mohamed K. Metwaly, Nagy I. Elkalashy, "Performance investigation of multi-level inverter for DFIG during grid autoreclosure operation", International Journal of Power Electronics and Drive System (IJPEDS) Vol. 10, No. 1, pp. 454 462, March 2019.

[19] D. Noel, F. Sozinho, D. Wilson and K. Hatipoglu, "Analysis of large-scale photovoltaic power system integration into the existing utility grid using PSAT," SoutheastCon 2016, Norfolk, VA, 2016, pp. 1-7.

[20] L. Campanhol S. Silva A. Júnior V. Bacon "Single-stage three-phase grid-tied PV system with universal filtering capability applied to DG systems and AC microgrids" IEEE Trans. Power Electron. 2017.

[21] S. Correia, S. F. Pinto and J. F. Silva, "Smart integration of Distributed Energy Resources in microgrids," 2017 International Young Engineers Forum (YEF-ECE), Almada, 2017, pp. 85-90

[22] R. Pillai, G. Ghatikar and A. Ahuja, "Integration of multivariate distributed energy resources for demand response: applications in the Indian scenarios," in CIRED - Open Access Proceedings Journal, vol. 2017, no. 1, pp. 18491852,102017

[23] Y. Yu, P. B. Luh, E. Litvinov, T. Zheng, J. Zhao and F. Zhao, "Grid Integration of Distributed Wind Generation: Hybrid Markovian and Interval Unit Commitment," in IEEE Transactions on Smart Grid, vol. 6, no. 6, pp. 30613072, Nov. 2015.

[24] F. Blaabjerg, Y. Yang, D. Yang and X. Wang, "Distributed Power-Generation Systems and Protection," in Proceedings of the IEEE, vol. 105, no. 7, pp. 1311-1331, July 2017.

[25] S. Ichoua, "A stochastic approach for the integration of distributed energy resources," 2014 IEEE International Technology Management Conference, Chicago, IL, 2014, pp. 1-4.

[26] A. Bag, B. Subudhi and P. K. Ray, "Grid integration of PV system with active power filtering," 2nd International Conference on Control, Instrumentation, Energy \& Communication (CIEC), Kolkata, 2016, pp. 372-376

[27] T. Geury S. Pinto J. Gyselinck P. Wheeler "An indirect matrix converter-based unified power quality conditioner for a PV inverter with enhanced power quality functionality" IEEE Innovative Smart Grid Technologies - Asia (ISGT ASIA) 2015.

Int J Pow Elec \& Dri Syst, Vol. 11, No. 2, June 2020 : 692 - 701 


\section{BIBLIOGRAPHY OF AUTHORS}

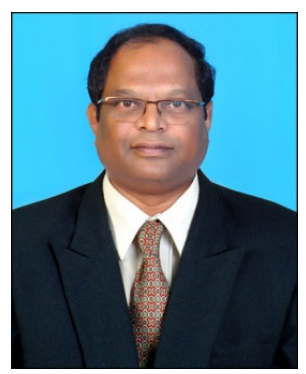

P.V.V. Satyanarayana was born in Andhra Pradesh, India in 1967. He received his B.Tech and M.Tech degrees in Electrical and Electronics Engineering from J.N.T.University Kakinada, A.P, India in 1993 and 2009 respectively. He also received his MBA degree from Osmania University, Hyderabad, India in 2013.

His employment experience included 4 years industry and 22 years teaching and currently working as Associate Professor in the department of Electrical and Electronics Engineering of Mahaveer Institute of Science and Technology, Hyderabad, India. His special fields of interest include Electrical Machines, Power Systems, Power Electronics, Non-conventional energy sources, HVDC and FACTS.

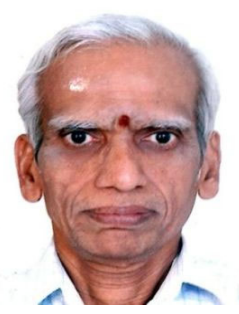

Dr. P.V. RAMANA RAO was born in India in 1946; He received the B.Tech degree in Electrical and Electronics Engineering from IIT Madras, India in 1967 and M.Tech degree from IIT Kharagpur, India in 1969. He received Ph.D from R.E.C Warangal in 1980. Total teaching experience 41 years at NIT Warangal out of which 12 years as Professor of Electrical Department. Currently Professor of Electrical Department in University college of Engineering and Technology, Acharya Nagarjuna University, Andhra Pradesh, India. His fields of interests are Power system operation and control, Power System Stability, HVDC and FACTS, Power System Protection, Application of DSP techniques and Application of Intelligent control techniques to Power systems. 